\title{
Climate Change Impacts and Local Adaptation Strategies at Chitlang, Makwanpur, Nepal
}

\author{
Garima Sharma ${ }^{1}$, Deepak Gautam ${ }^{1,2^{*}}$, Catherine Mhae B. Jandug2,3, Suman Bhattarai1,2, DhrubaBijaya G. C1,
} Keshab Baral ${ }^{1}$, Bikram Manandhar ${ }^{1}$, Rajesh Sigdel ${ }^{1}$

1 Institute of Forestry, Tribhuvan University, Nepal

${ }^{2}$ College of Forestry, Beijing Forestry University, Beijing 100083, China

${ }^{3}$ College of Forestry and Environmental Science, Caraga State University, Philippines

\section{*Corresponding Author}

Deepak Gautam

\section{Article History}

Received: 19.11 .2019

Accepted: 26.11.2019

Published: 30.12 .2019

\begin{abstract}
Climate change is one of the most serious threats to natural resources and livelihoods. Key informant interview $(n=3)$, focus group discussion $(n=3)$ and household survey $(n=60)$ were undertaken to access the impacts of climate change on livelihood, local people's perception of climate change and the local adaptation measures used by the people. Meteorological data from 1981 to 2010 were used to analyze climatic trends. The meteorological data shows annual maximum and minimum temperature is in increasing trend whereas annual rainfall is erratic in nature. The study revealed that the major threats prevailing in the study area were drought, storm, thunder and lightning, pest attack on crops and outbreak of disease. Decreased agricultural production, shortage of water, increased livestock disease and forest fires were the problems faced. Although the majority of people were not aware of the climate change and its adaptation strategies, they have been traditionally practicing adaptation strategies like change in cropping pattern, change in crop varieties, use of more organic fertilizer, supplemental irrigation, rainwater harvesting, improving livestock shed and ponds, removal of invasive species, etc.
\end{abstract}

Keywords: Perception, Meteorological data, Temperature, Erratic Rainfall, Copping.

\section{INTRODUCTION}

Climate change is no longer a subject of theoretical meteorology, but it is a real issue affecting almost all the lives and activities on the earth. According to IPCC [1] reports from 1906 to 2005 the global average surface temperature increased by $0.74^{\circ} \mathrm{C}$. The linear warming trend over the 50 years from 1956 to 2005 was $0.13^{\circ} \mathrm{C}$ per decade is nearly twice that for 100 years from 1906 to 2005. IPCC has also projected that by 1990 global average surface temperature will increase by $1.8-4.0^{\circ} \mathrm{C}$. According to IPCC [1] summary report, 11 of the last 12 years (1995-2006) rank among the warmest years in the instrumental record of global surface temperature since 1850 .

Although Nepal is responsible for only about $0.025 \%$ of the total annual GHG emissions of the world Nepal cannot escape the rapidly increasing influence of climate and global changes [2]. According to the record of the Department of Hydrology and Meteorology, the average temperature of Nepal was increased by $1.8^{\circ} \mathrm{C}$ per annum during the period of 1975 to 2006 . Now the average temperature rise is estimated at $0.5^{\circ} \mathrm{C}$ per decade, which is very high, compared to other developing countries. The quickly thinning glaciers (average retreat of more than $30 \mathrm{~m} /$ year), the rapid rise in temperature $\left(>0.06^{\circ} \mathrm{C}\right)$, erratic rainfalls and increase in the frequency of extreme events such as drought and flood-like condition are some of the effects our country is facing during the last few years. Impacts of climate change are worsened by geographical location, rugged topography, social condition, political influence, lack of skilled manpower, illiteracy and economic prosperity, nature dependent livelihood and poverty [3, 4].

Climate change is not an isolated issue; it is intimately connected to other recognized natural hazards and global environmental problems. The most likely impacts of climate change that will be experienced will be more severe water stress and overheating. Other widely discussed impacts include snowmelt, glacier retreat, a shift in weather patterns, intensification of droughts

Copyright @ 2019: This is an open-access article distributed under the terms of the Creative Commons Attribution license which permits unrestricted use, distribution, and reproduction in any medium for non commercial use (NonCommercial, or CC-BY-NC) provided the original author and source are credited. 
and desertification, flooding, fires, species shift, the rise of disease incidence and sea-level rise. The temperature and rainfall affect the livelihood assets of the local people. Specifically, natural assets like forest biodiversity, human health, and water resources have been affected due to variation in rainfall and temperature and agricultural production has also been affected. Therefore, this study attempted to observe the impacts of climate change on local livelihood and the adaptation measures carried out by them.

\section{Materials and Methods \\ Study Area}

The study was carried out in ward no 9 of Chitlang which lies in Makwanpur district, surrounded by Markhu in South, Bajrabarahi in West, Naubise and Thankot in North and Fakhel and Matatirtha in East. It comprises a total of 647 households. The total population of the ward is 2666 with male population 1170 and female population 1496.

\section{Geographic location \\ Latitude: $\quad 27.6421^{\circ} \mathrm{N}$ \\ Longitude: $85.1790^{\circ} \mathrm{E}$ \\ Elevation: $1833 \mathrm{~m}$}

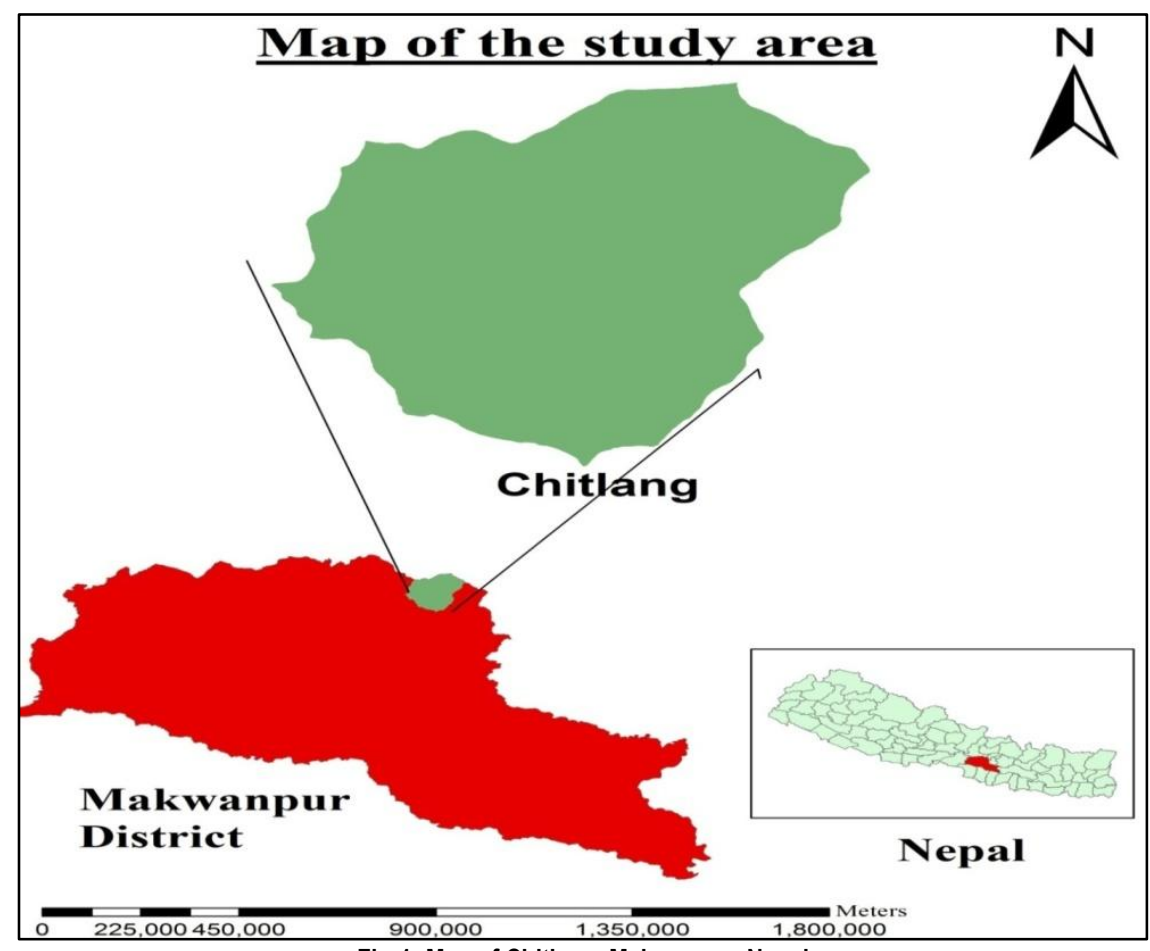

Fig-1: Map of Chitlang, Makwanpur, Nepal

\section{Data COLlection}

Direct observation of the sites affected by climate change like drying out water source, crop failure due to lack of soil moisture was made during the field visit with one local people. The local adaptation was also observed during the transect walk. Out of 647 households, 60 households were chosen randomly for the questionnaire surveys. Key informant interviews ( $n=3$ ) were conducted with village leaders, senior citizens who have been living in the study area for a long time. Focus group discussions ( $n=3$ ) were conducted to gather information on past natural disaster events in the area, observe environment changes in recent years, adaptation measures adopted by local people. Meteorological data of 30 years (from 1981 to 2010) were collected from the nearest meteorological station.

\section{DATA ANALYSIS}

The least-squares curve fitting technique was used to find a linear trend of temperature and rainfall [5]. Collected data from field were analyzed using both quantitative and qualitative methods by using SPSS and MS Excel and presented by various illustrations such as figures, graphs and charts. Arc GIS10.2.2 was used to make a map of the study area. 


\section{RESULTS AND DISCUSSION}

\section{People's Perception of Climate Change}

Based on our household survey out of total respondents only $37 \%$ heard about climate change and climate-related information, rest $63 \%$ were unknown about climate change and other climate-related information. $88 \%$ of people noticed increased in average temperature compared now to 10 years ago, whereas $12 \%$ of people said there is no change in average temperature. $88 \%$ of people reported that summer temperature is increasing and $12 \%$ denied it. Similarly, $12 \%$ of the respondents said that there is no change in winter temperature, $83 \%$ said that winter temperature is increased and $5 \%$ said winter temperature is decreased. Likewise, $77 \%$ reported there is an increase in the erratic event of rainfall, $20 \%$ reported there is no change and $3 \%$ is against it. $13 \%$ of the respondents reported there is no change in thunderbolts events and $87 \%$ reported it is increased now compared to 10 years ago. According to our study, the main hazard of locality is drought. Out of 60, 59 respondents (98\%) reported drought is felt in the study area. $73 \%$ of people agreed storm is another hazard faced in the locality. Similarly, $75 \%$ of the respondents said that thunder and lightning are faced more. $70 \%$ agreed on hail as another hazard. Also, the pest attack on crops is another major hazard. $95 \%$ of the respondents reported it. $23 \%$ of the respondents believed that the outbreak of disease is the main hazard but $77 \%$ denied it. Lastly, there was no evidence of flood and landslide.

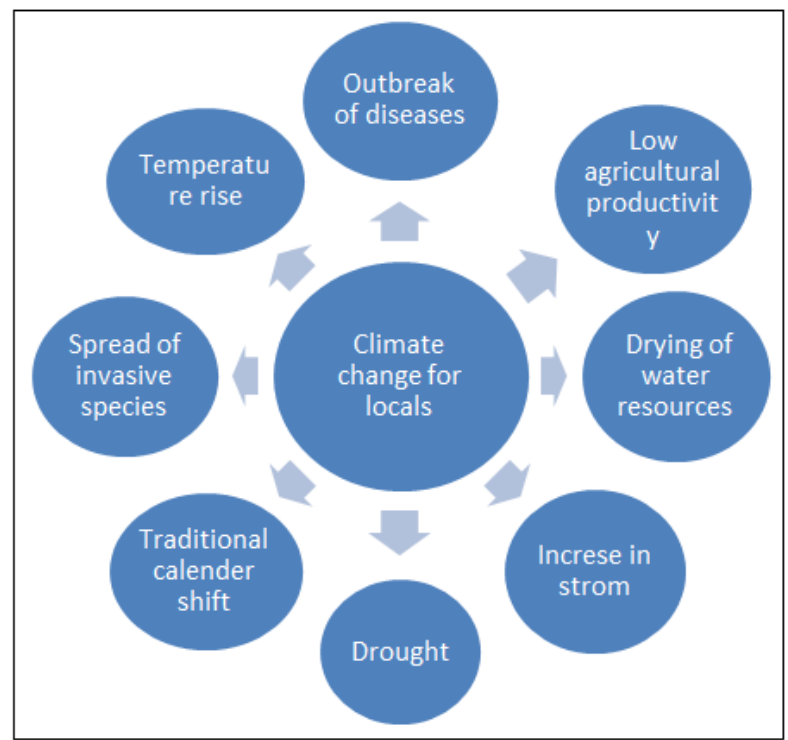

Fig-2: Local indicators of climate change based on people's perception

\section{Variation in Temperature and Precipitation}

Nepal's temperature is rising by about $0.41^{\circ} \mathrm{C}$ per decade [6]. The mean maximum temperature in Nepal increased by $0.06^{\circ} \mathrm{C}$ per year between 1977 and 2000 [7]. The maximum and minimum annual temperature showed an increasing trend. The highest record of maximum temperature was $29.5^{\circ} \mathrm{C}$ in 1983 (May) and 2008 and the lowest was $-7.5^{\circ} \mathrm{C}$ in the year 1983 (January). Other high records of temperature were increased to $29^{\circ} \mathrm{C}$ in 1985 and $2009,28.6^{\circ} \mathrm{C}$ in 1998 and $28{ }^{\circ} \mathrm{C}$ in 1999 and 2006 as shown in Figure-3. The differences in maximum temperature were about $4^{\circ} \mathrm{C}$ between the temperature between 1981 and 2010 . Hence, higher records of temperature in these years were the indication of the drought period.

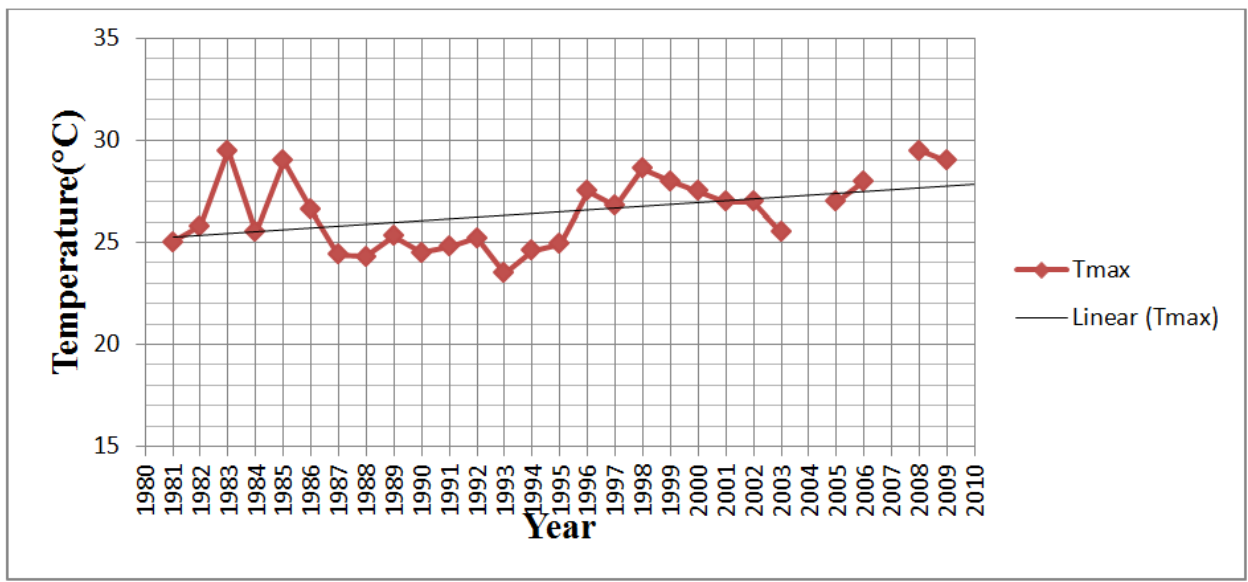

Fig-3: Annual Maximum Temperature 


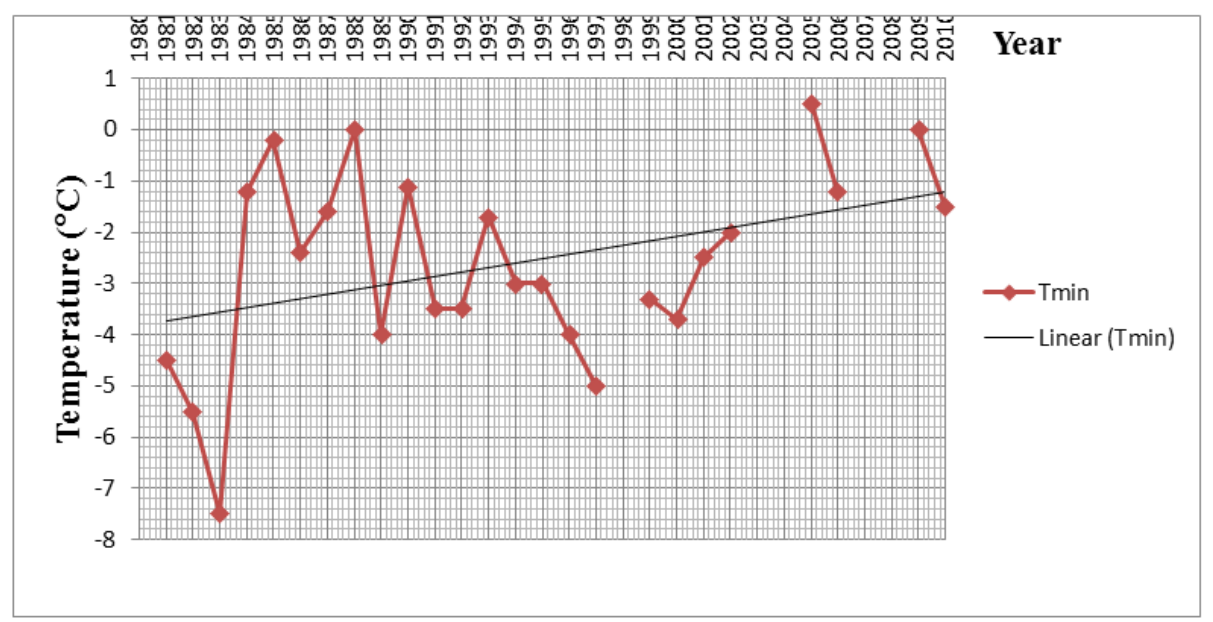

Fig-4: Annual minimum Temperature

Figure-4 shows that minimum temperature of initial year i.e. 1981 was recorded about $-4.5^{\circ} \mathrm{C}$. The minimum temperature in 2010 was $-1.5^{\circ} \mathrm{C}$. The differences in the minimum temperature were by $3^{\circ} \mathrm{C}$ between temperature of 1981 and 2010 . The minimum temperature was also up to $0.5^{\circ} \mathrm{C}$ in the year 2005 . In the similar research in Pokhara, the maximum mean temperature and minimum mean temperature was increasing at the rate of $0.0490^{\circ} \mathrm{C}$ and $0.040{ }^{\circ} \mathrm{C}$ respectively during the year 1981 to 2010 , where overall temperature was found to be increased at the rate of $0.0455^{\circ} \mathrm{C}$ annually [5].

\section{Variation in Rainfall}

The highest and the lowest annual precipitation sites of Nepal are Lumle Kaski, and Lomanthang, Mustang [8]. Pokhara also receives the highest amount of rainfall [9]. MakwanpurHetauda also receives high amount of rainfall buts its pattern is fluctuating year by year. The rainfall distribution was one of the major elements to analyze the climatic situation of the study area. Study of rainfall data available from the Department of Hydrology and Meteorology of last 30 years (1982-2011) period was used to analyze the rainfall pattern. The rainfall pattern of the study area is erratic in nature. The variation of rainfall was because of the differences in precipitation in rainy season. Figure- 5 shows the trend of rainfall in the study area, which was the highest in 1999 i.e. $2576.6 \mathrm{~mm}$ and lowest in year 2010 i.e. $1029.7 \mathrm{~mm}$.

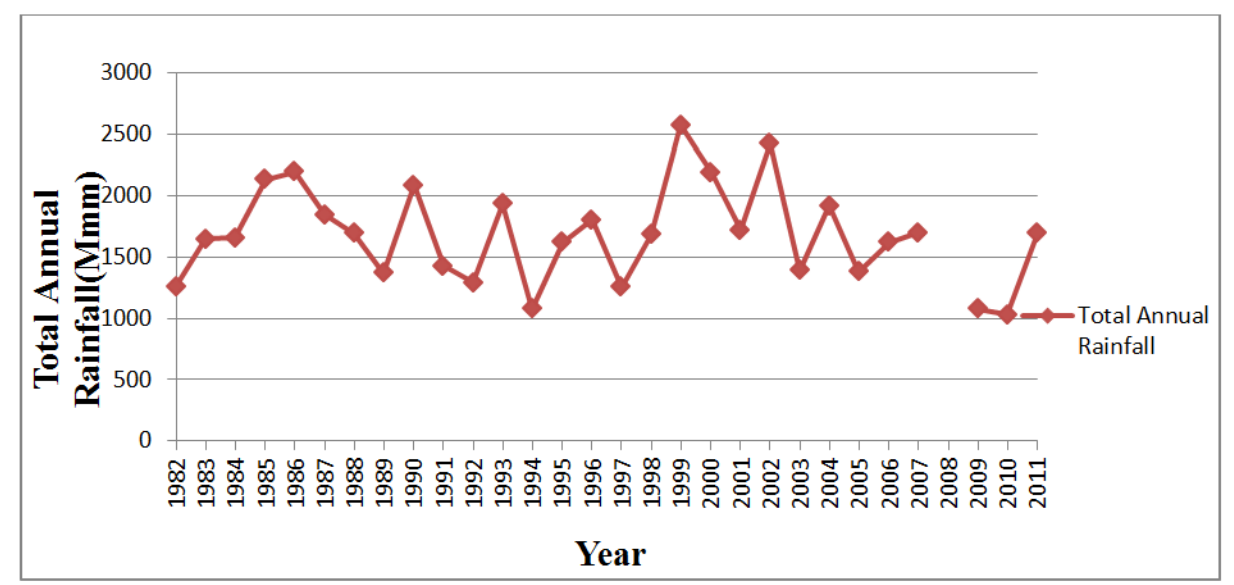

Fig-5: Trend of rainfall pattern

\section{Impacts of Climate Change}

The agriculture productivity of Nepal is declining and conditions may further be exacerbated due to climate change and its unwanted impacts. Warming of the globe more than $2.5^{\circ} \mathrm{C}$ could reduce global food supplies and contribute to higher food prices [1]. The agriculture sector was mostly affected by untimely rainfall with high intensity [10]. Gautamet al., [5] also found that precipitation trend was increasing but monsoon and winter precipitation was decreasing, which directly affects the agricultural productivity and farmer's calendar. In our study, the production of rice (Oryza sativa), potato (Solanumtuberosum), pea (Pisumsativum), and maize (Zea mays) is decreasing for many years. The main reason for the decrease in production is the change in rainfall patterns and increased drought period. Out of total respondents, $77 \%$ said that the overall agricultural production is decreased, $18 \%$ reported that agricultural production is the same as before and only $5 \%$ believed that agricultural production is increased. According to key informants, many crops like maize, rice, potato during sowing and germination drought and change in rainfall patterns were the 
serious hazards and during growth and harvesting pest attack on crops and outbreak of disease were main threat. (E.g. Laai in many vegetable crops, Dadhuwa in potato and grasshopper in maize).

There is a high fluctuation in rainfall in different months [9]. In the study area, while asking about the change in water resources $90 \%$ of the respondents reported that there is a shortage of drinking water over the last year of time and $10 \%$ believed there is no shortage of drinking water. Similarly, out of total respondents, $54 \%$ believed that the quality of drinking water is decreased than before, whereas $43 \%$ said quality is the same and $3 \%$ said the quality of drinking water is increased. The effect of climate change seems more serious to women as they had to spend more time to collect drinking water and household use water. People have to bear more costs due to a shortage of water. As a result, it directly affects the financial condition of the people. Due to changes in rainfall patterns and late monsoon people provide supplemental irrigation which causes them additional expenditures. Respondents reported that there has been the introduction of more livestock diseases which they have never heard before, but at the same time, they also claim that due to advancement in the medicinal facilities there is a decline in the physical losses. This causes them to bear the additional cost. Forest is another sector on which climate change has serious impacts. As temperature rise, weather patterns and the availability of the water also changes, thus putting more stress on trees for their survival. The observed changes seen in the forest are frequent forest fires, increased pest attack and increased incidence of diseases of plants and animals including human beings. Diseases like Malaria, Japanese encephalitis, dengue as well as allergies and itching problems are increasing day by day [9]. It's all due to temperature favorable for mosquito breeding.

Plants and animals introduced in an area where they do not naturally occur are called alien, exotic or non-native [12]. 21 invasive species are highly problematic species [11]. Invasive species like Lantana camera and Chromolaenaodorata and Mikaniamicrantha are common in Nepal [9]. According to $80 \%$ of respondents, the presence of invasive species is increased now compared to 10 years ago.

\section{Adaptation Strategies Adopted at the Local Level}

For agriculture and livestock, $65 \%$ of the respondents said that they had made a change in cropping patterns as an adaptation measure for climate variability. $52 \%$ of the respondents introduce new crops/ varieties. $75 \%$ of the respondents said supplemental irrigation is another measure to cope up with impacts. Likewise, $78 \%$ of respondents use more organic fertilizer to increase production. $7 \%$ of the respondents shifted to nonfarm activities and due to late monsoon and change in rainfall pattern, $75 \%$ of the respondents' plant crops later. $69 \%$ of the respondents claimed that animal sheds and ponds are improved. Only $18 \%$ of the respondents said that they have shifted to non-farm activity as adaptation measures and $78 \%$ of the respondents have medicated and vaccinated livestock in order to protect from disease. Similarly, in the case of water resources, $68 \%$ of the respondents improve the water recharge system, $52 \%$ of the respondents maintain and protect their water resources and $38 \%$ of the respondents do rainwater harvesting as an adaptation measure. People there practice cleaning and weeding activities for the reduction of fire hazards and invasive species. $27 \%$ conserve rare and threatened species and $47 \%$ of the respondents remove invasive species as a local strategy to adapt the negative impact of climate change. In cheuchekhola, Makwanpur also people adopted different strategies to enhance their income (13).

\section{CONCLUSION}

Local dwellers have knowingly and unknowingly experienced unusual changes in temperature and rainfall patterns which were supported by a number of indicators such as rise in temperature, erratic rainfall, drought, storms, low agricultural productivity, outbreak of disease and pests to human and their livestock, spread of invasive species, drying of water resources and shifting of traditional calendars. These indicators made local livelihood more vulnerable and fragile. Although many people were unaware of the climate change and climate variability they have been traditionally practicing adaptation strategies like change in cropping pattern, change in crop varieties, use of more organic fertilizer, supplemental irrigation, rainwater harvesting, improving livestock shed and ponds. So, local adaptation-based resource management practices through training and education are recommended to minimize the vulnerability and sustain the livelihood of the local people.

\section{ACKNOWLEDGMENTS}

We are grateful to all helping hands, reviewers, and editors for their valuable comments and suggestions. We are also grateful to the local people of Chitlang ward no 9, Mr. Gun Bahadur KC, Secretary of Chitlang ward no. 9, field assistant RashmitaParajuli for her support.

\section{Conflict of interest: The author declares no conflict of interest}

\section{REFERENCES}

1. IPCC. (2007). Climate Change Adaptation and Vulnerability, Summary for Policymakers, Intergovernmental Panel on Climate Change, Geneva, Switzerland. 
2. Karki, M. B. (2007). Nepal's experience in climate change issues fourth Asia pacific seminar on climate change, Sydney Australia.

3. Gurung, G. B., \&Bhandari, D. (2009). Integrated Approach to Climate Change Adaptation. Journal of Forest and Livelihood, 8(1):90-99.

4. Anup, K. C., Bhandari, G., Joshi, G. R., \&Aryal, S. (2013). Climate change mitigation potential from carbon sequestration of community forest in mid hill region of Nepal. International Journal of Environmental Protection, 3(7), 33-40.

5. Gautam, D., Bhattarai, S., Sigdel, R., Jandng, C., M. B., Mujahid, A., G. C., \& D. B. (2019). Climate variability and wetland Resource in Rupa Lake Catchment, Nepal. http://twasp.info/journal/home. https://doi.org/10.5281/zenodo.3568477

6. SAGUN. (2009). Climate Change Impact on Livelihood of Poor and Vulnerable Communities and Biodiversity conservation: A case study in Banke, Bardia, Dhangadi and Rasuwa districts of Nepal.

7. ICIMOD. (2009). Climate change Vulnerability of Mountain ecosystems in the Eastern Himalaya, Kathmandu Nepal.

8. Gauchan, A. (2010). Household Level Adaptation Strategies to Climate change impacts in Mustang district. A case study from Lete VDC, Lower Mustang. A M.Sc. research thesis Tribhuva, University, Institute of Forestry, Pokhara, Nepal.

9. Gautam, D. (2011). Impact of Climate Change on wetland resources and Livelihood in Rupa Lake Area. M.Sc. Natural Resource Management and Rural development Thesis, Tribhuvan University, Institute of Forestry, Pokhara, Nepal.

10. Koirala, M., \&Bhatta, R. (2010). Communities challenges and climate change A case studies from Nepal: Communities understanding and adaptation for climate change.

11. Pokhrel, H.R., Gautam, D., Jandug, CM.B., Bhattarai,S., Baral, K., Bhandari, J., Gahatraj,G. (2019).Status and Diversity of Invasive Alien Plant Species in Rupa Lake, Kaski District, Nepal. www.jetir.org (ISSN-2349-5162. DOI:

http://doi.one/10.1729/Journal.22839

12. Tiwari, S., Adhakari, B., Siwakoti, M., \&Subedi, K. (2005). An inventory and assessment of invasive alien plant species Nepal, IUCN.

13. Dahal, D., Gautam, D., Bhattarai, S., Khanal, L., Baral, K.,Acharya, K.R. (2019). Potentiality of Pangolin based Ecotourism in Chuchhekhola Community Forest, Makawanpur, Nepal. www.jetir.org (ISSN-2349-5162.

DOI: http://doi.one/10.1729/Journal.22838 